\title{
Capacity cost structure, welfare and cost recovery: are transport infrastructures with high fixed costs a handicap?
}

\author{
Bruno De Borger, Fay Dunkerley and Stef Proost*
}

\begin{abstract}
$\underline{\text { Abstract }}$
In this paper, we consider a region that invests in infrastructure used by both local demand and through transport. We then compare transport systems that have, for a given capacity, the same total infrastructure cost but vary in the proportion of fixed costs and variable capacity costs. We show, first, that infrastructure which has (ceteris paribus) a higher share of fixed costs leads to higher welfare for the regional government building it. Contrary to what is commonly believed, it therefore requires less, rather than more, federal subsidies. Second, we find that, even for capacity characterized by, ceteris paribus, very high shares of fixed costs, financing of infrastructure is generally not an important issue as long as regions are allowed to toll through traffic. Third, if member states cannot toll through traffic, or if a federal authority (such as the EU or the USA) can impose pricing at the global marginal social cost, our analysis shows that this reduces investment incentives for the individual regions, and subsidies may be needed. We discuss the policy implications of these findings and illustrate all theoretical results numerically.
\end{abstract}

JEL: R41, R48

Keywords: capacity cost structure, cost recovery, transport investment

*De Borger: Department of Economics, University of Antwerp, Prinsstraat 13, B-2000 Antwerp, Belgium (bruno.deborger@ua.ac.be); Dunkerley: Department of Economics, Catholic University of Leuven, Naamsestraat 69, B-3000 Leuven ( fay.dunkerley@econ.kuleuven.ac.be); Proost: Department of Economics, Catholic University of Leuven, Naamsestraat 69, B-3000 Leuven, Belgium (stef.proost@econ.kuleuven.ac.be). We acknowledge the financial support of the 6 th Framework research Program of the EC (6.2)) on the Funding of the Trans European Networks (www.econ.kuleuven.be/funding). We benefited from useful comments on an earlier version by Robin Lindsey 


\section{Introduction}

Both in academic and policy circles it is often argued that there are two reasons why the provision and funding of transport capacity in a country or region may be quite problematic. First, if a region faces a lot of through traffic, it will have limited incentives to invest, unless it can charge high tolls on through traffic (see, e.g., De Borger,Dunkerley, Proost (2007)). The reason is that, when making decisions, the regional government typically cares about the welfare of the local users of the infrastructure, the costs of capacity investments and possible revenues from user charges; however, it is likely to take into account neither the benefits of the infrastructure for foreign users nor their time losses due to possible congestion. Since any benefits from investment partially flow abroad, in the form of time gains for through traffic, this results in inefficiently low investment.

Second, funding of infrastructure capacity may be difficult when there are high fixed costs of capacity expansion. This argument goes back to the literature on cost recovery of transport investments (see, e.g., Mohring and Harwitz (1962), Small (1982), and Arnott and Kraus (1998)). This literature considers a decision maker interested in optimal investment in transport capacity and optimal user charges for use of the infrastructure. It shows that, if use of the infrastructure is priced at marginal social cost, the degree of cost recovery of an optimal transport investment strongly depends on the cost structure of capacity expansion. For example, assuming perfectly divisible capacity and a user cost function that is homogeneous of degree zero in volume and capacity (i.e., cost depends on the volume-capacity ratio only), optimal pricing implies exact cost recovery if there are constant returns to scale in capacity provision. More generally, the cost recovery ratio equals the elasticity of the capacity cost function with respect to capacity so that, for infrastructure with increasing returns to scale involving high fixed costs, deficits result ${ }^{1}$. The policy implication of this literature is that the funding of capacity investments may be problematic for

\footnotetext{
${ }^{1}$ As shown in Morrisson (1983), Zhang and Zhang (2003), and de Palma and Lindsey (2007), these results have to be amended when the underlying assumptions do not hold. The overall message remains broadly the same, however.
} 
infrastructures with high fixed costs; subsidies may be needed to implement marginal cost pricing ${ }^{2}$.

The above arguments have strongly influenced actual policy making. The reduction in investment incentives by local governments when through traffic is important has been one of the principle motivations in the EU and the US to subsidize interstate or cross-border transport investments. Moreover, the difficulty of cost recovery and the associated funding problems in the case of high fixed cost infrastructures largely explains recent policies in the EU, where member countries can apply for federal grants for their cross-border infrastructure projects within the framework of the Trans European Networks (TEN's). So far, the focus of these subsidies has been much more on rail and inland waterway investments (infrastructures with high fixed costs) than on road.

The purpose of this paper is to reconsider the role of the cost structure of capacity investments and of the presence of through traffic for investment incentives, for welfare and for cost recovery. This seems desirable for several reasons. First, the literature stressing the role of high fixed capacity costs has almost exclusively focused on issues of cost recovery, and much less on the welfare effects of different cost structures. For example, a relevant unanswered question is whether infrastructures with high fixed capacity costs (e.g. rail) generate more welfare for a region, and will therefore more easily be build, than an infrastructure with close to constant returns to scale in capacity expansion (e.g., roads)? Second, the available cost recovery theorems have been derived in a setting where a policy maker for a single region decides on capacity and pricing of an infrastructure that is only used by local transport; optimal pricing then implies charging users at marginal social cost. When countries face through transport, however, the literature shows that they will, in the absence of regulation, charge prices above the marginal social cost. This 'taxexporting' behavior allows them to generate more revenues on through traffic (see Arnott and Grieson (1981) and, in a transport setting, Levinson (2001) and De Borger, et al.(2007)). It is intuitively clear that the relation between the cost structure of capacity investment and revenues through user charges may then become much more

\footnotetext{
${ }^{2}$ Whether or not scale economies in capacity provision strongly reduce investment incentives in practice depends on the cost for the government to generate public funds. As long as a government can rely on public revenue that is not too costly, high fixed costs in capacity provision may not prevent implementation of the ideal investment and pricing combination, whatever the structure of the cost function.
} 
subtle than in the case without through traffic. It will not only depend on the capacity cost structure but also on countries' autonomy is deciding on tolls for infrastructure use.

In this paper, we therefore study the relation between the cost structure of capacity expansion (i.e., the relative share of fixed costs), welfare and cost recovery in a setting where an infrastructure is used both by local users and by through traffic. Prototype examples of such a setting is a country within the EU or a state in the USA. We obtain several interesting results. First, we show that infrastructures that have, for a given total cost, a large fixed cost component, are beneficial to a welfare maximizing country. Therefore, countries have higher incentives to invest so that, contrary to what is commonly believed, such investments require less, rather than more, federal subsidies. This result is shown to hold both in the case with and without through traffic. Second, in the case with both local and through traffic demand we find that, even for capacity characterized by very high shares of fixed costs, financing of infrastructure is generally not an important issue as long as regions are allowed to toll the use of the infrastructure. When the infrastructure can be priced by the regional governments, it is therefore no longer clear whether a high share of fixed costs of capacity expansion is a hurdle for the funding of investments. If the regional government is restricted (e.g., by regulation imposed by a higher-level federal government such as the EU) in its pricing policies, this reduces regions' investment incentives and subsidies may be justified. In general, whether funding problems arise depends, among others, on who is responsible for toll and capacity decisions, on the importance of through traffic, and on the structure of the capacity cost function.

These results have clear policy implications. For example, they suggest that the EU's emphasis of subsidies for cross-border infrastructures with high fixed costs may be misguided. Moreover, they suggest that the EU should not subsidize the provision of infrastructure at all in countries facing substantial through traffic and tolling can be decided by the member states. Finally, if member states cannot toll through traffic, or if the EU can impose socially optimal pricing on the transport corridor, then subsidies may well be justified to stimulate investment incentives.

The paper is structured as follows. Section 1 discusses the model set up. Section 2 discusses the case of one isolated region with and without through traffic. Section 3 illustrates with a numerical example the importance of the cost structure. A final section concludes. 


\section{Model formulation}

In this section, we formulate the model to analyze the role of the cost structure (presence of high fixed costs of capacity expansion) for investment decisions, for cost recovery and for welfare. It is assumed that the infrastructure is build and operated by a region that faces both local and through traffic. We use a model set up close to De Borger et al. (2007), but as they use a proportional capacity cost structure, they neglect issues related to the structure of the cost function.

\subsection{Demand, prices, and user cost specification}

Demand for local transport in a given region is represented by the strictly downward sloping and twice differentiable inverse demand function $P^{Y}(Y)$, where $Y$ is the demand for transport in the region by local inhabitants. Overall demand for through traffic through A is described analogously by the strictly downward sloping inverse demand function $P^{X}(X)$, where $X$ is the through traffic flow. Note that prices are generalised prices; they include resource costs, time costs, and possible user charges. We focus throughout on the case where user charges are the same for local and through traffic ${ }^{3}$. The uniform toll is denoted by $\theta$.

The generalised user costs for local transport and for through traffic, denoted as $g^{Y}$ and $g^{X}$ respectively, equal the sum of the time and resource costs of travel, plus the toll. Since local and through traffic both use the same infrastructure, we have:

$$
\begin{aligned}
& g^{Y}=C(q)+\theta . \\
& g^{X}=C(q)+\theta
\end{aligned}
$$

In these expressions, $C($.$) is the time plus resource cost, assumed to depend on the$ volume-capacity ratio $q=\frac{V}{Z}$. Here $V=X+Y$ is the total transport volume, and $Z$ denotes capacity. The user cost function is twice differentiable and strictly increasing in the total traffic volume relative to capacity.

\footnotetext{
${ }^{3}$ We briefly report on the results for other pricing structures (e.g., toll differentiation between local and through traffic) at the end of Section 2. There we also discuss a more general setting of a transport corridor with several regions that engage in tax competition. This does not change the main insights from the analysis.
} 
In the absence of corner solutions, transport equilibrium for through traffic and local traffic implies equality between generalized prices and costs:

$$
\begin{aligned}
& P^{X}(X)=g^{X}=C(q)+\theta \\
& P^{Y}(Y)=g^{Y}=C(q)+\theta
\end{aligned}
$$

Differentiation of this system of equilibrium conditions and solving by Cramer's rule implies the following partial effects of toll and capacity changes on demands:

$$
\begin{aligned}
& \frac{\partial X}{\partial \theta}=\frac{1}{\Delta} \frac{\partial P^{Y}}{\partial Y}<0 ; \quad \frac{\partial Y}{\partial \theta}=\frac{1}{\Delta} \frac{\partial P^{X}}{\partial X}<0 \\
& \frac{\partial X}{\partial Z}=-\frac{1}{\Delta} \frac{\partial P^{Y}}{\partial Y} \frac{C^{\prime} V}{Z^{2}}>0 ; \quad \frac{\partial Y}{\partial Z}=-\frac{1}{\Delta} \frac{\partial P^{X}}{\partial X} \frac{C^{\prime} V}{Z^{2}}>0
\end{aligned}
$$

where $C^{\prime}=\frac{\partial C(q)}{\partial q}>0$, and $\Delta=\frac{\partial P^{X}}{\partial X} \frac{\partial P^{Y}}{\partial Y}-\frac{C^{\prime}}{Z}\left(\frac{\partial P^{X}}{\partial X}+\frac{\partial P^{Y}}{\partial Y}\right)>0$. As expected, a higher toll in the region implies lower demand for both local and through traffic. A capacity increase raises both demands.

\subsection{Capacity costs and the isocost- isocapacity locus}

To model different cost structures for capacity expansion, we have chosen for the simplest possible approach. Different degrees of returns to scale are captured by a linear capacity cost function. Let $C(Z)$ represent total capacity cost, then the cost function is given by:

$$
C(Z)=F+k Z
$$

In this expression, $F$ is a fixed cost and $k$ is a constant marginal cost of capacity expansion. The degree of returns to scale can then be varied by changing, for a given $\mathrm{Z}$, the share of the fixed and variable costs, i.e., by manipulating the parameters $\mathrm{k}$ and $F$. To see this, note that the degree of returns to scale can be measured by the inverse of the cost elasticity with respect to capacity:

$$
R T S=\frac{1}{\eta}=\frac{F+k Z}{k Z}
$$

where $\eta$ is the cost elasticity: $\eta=\frac{\partial C}{\partial Z} \frac{Z}{C}$. This specification therefore implies constant returns if the fixed capacity cost is zero; increasing the relative importance of the fixed cost yields a higher degree of increasing returns. 
To study the implications of differences in the cost structure of capacity provision between, say, road and rail, it will be instructive to introduce the concept of an isocost-isocapacity locus $\left\{\mathbf{C}^{\circ}, \mathbf{Z}^{\circ}\right\} \equiv\left\{\mathbf{F} \geq \mathbf{0}, \mathbf{k} \geq \mathbf{0}: \mathbf{F}+\mathbf{k} \mathbf{Z}^{\circ}=\mathbf{C}^{\circ}\right\}$. It is defined the set of linear capacity cost functions that have the same total capacity cost $\mathrm{C}^{\circ}$ for a given level of capacity $\mathrm{Z}^{\circ}$. The concept is illustrated in Figure 1. For a reference level of capacity $\mathrm{Z}^{\circ}$ and a total cost level $\mathrm{C}^{\circ}$, we can define all combinations of marginal capacity costs $\mathrm{k}$ and fixed costs $\mathrm{F}$ that generate the same total cost $\mathrm{C}^{\circ}$. All such combinations are given by a linear relation. Intersection of the isocost-isocapacity locus with the vertical axis reflects an infrastructure with zero fixed capacity costs but high marginal capacity expansion cost $k_{1}$, so that $C\left(Z^{0}\right)=k_{1} Z^{0}$. The intersection with the horizontal axis reflects the extreme case of an infrastructure which can be expanded at zero marginal $\operatorname{cost}^{4}$; there is just a fixed cost $C\left(Z^{0}\right)=F_{1}$. Varying the fixed and variable cost parameters allows us to describe, along this locus, a wide range of capacity cost structures in terms of the relative shares of fixed and variable costs in total costs. For example, for given $Z^{\circ}$, rail infrastructure will typically be situated much further to the right than road infrastructure, which has a lower fixed cost share.

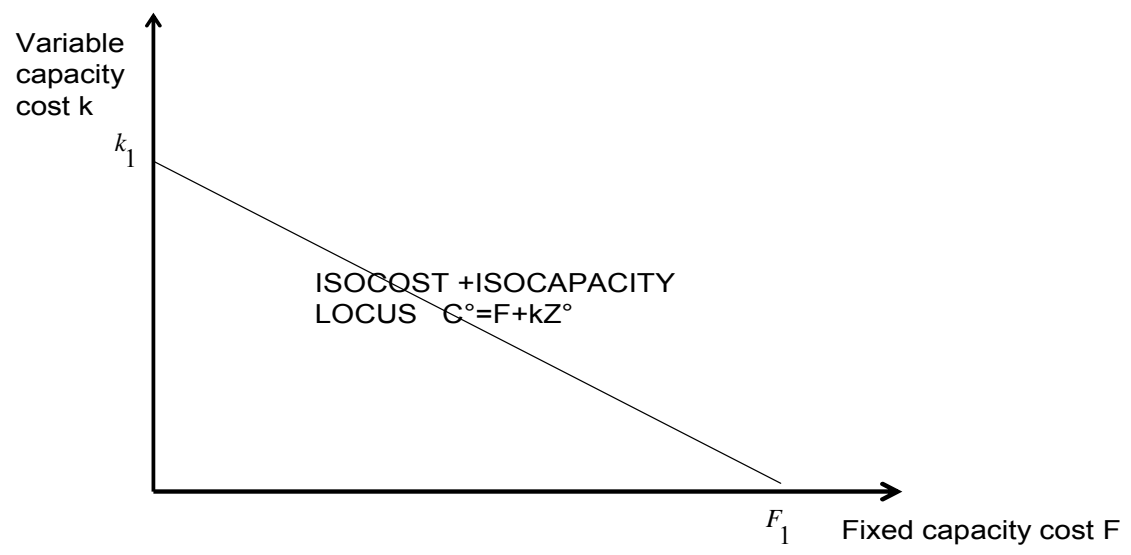

Figure 1: Isocost-isocapacity locus

\footnotetext{
4 In the latter extreme case, of course, the notion of capacity and congestion looses its standard meaning, since capacity can be expanded without extra cost.
} 


\subsection{The objective function of the government}

We assume that the objective function of the regional government captures the benefits for local users (net of user costs), toll revenues and capacity costs:

$$
W_{\text {reg }}=\int_{0}^{Y} P^{Y}(y) d y-g^{Y} Y+\theta(Y+X)-F-k Z
$$

Note that we assume the regional government ignores the user benefits of foreign users; only the revenues they yield are taken into account (and their contribution to congestion, via the generalized prices). Of course, a higher-level government (say, the EU or the federal level in the USA) that would capture also the benefits for through traffic in the region would judge policies differently. Such a "federal" objective function can be formulated as follows:

$$
W_{\text {fed }}=\int_{0}^{Y} P^{Y}(y) d y-g^{Y} Y+\theta Y+\int_{0}^{X} P^{X}(x) d x-g^{X} X+\theta X-F-k Z
$$

\section{The structure of capacity costs, welfare and cost recovery: theoretical analysis}

In this section, we assume the region is responsible for pricing and capacity decisions. We then study what the implications are of differences in the share of fixed capacity costs for capacity provision, for welfare of the region, and for the cost recovery ratio. To do so, let us assume that for a benchmark constant returns to scale cost structure (zero fixed capacity costs), it is optimal for the regional government to provide positive transport capacity $(Z>0)$. For this given capacity, we then analyze what happens when we alter the cost structure, along the isocost-isocapacity locus, towards higher shares of fixed capacity costs. To make the intuition of the results to be derived as transparent as possible, we proceed in several steps. We first consider the effect of altering the cost structure in the case of an isolated region without foreign traffic; a next step introduces through traffic. Finally, we briefly discuss extensions of the analysis to other settings.

\subsection{The case of a single region with only local demand}

Suppose an isolated region only has local transport. It decides on investment and transport tax levels by maximizing regional welfare. Now start from the 
benchmark case with zero fixed infrastructure costs, and then decrease the variable cost (hence raise the fixed cost above zero) along the isocost-isocapacity line. Graphically, starting on the intersection with the vertical axis, we consider a movement from left to right along the linear relation depicted in Figure 1. We formally show in Appendix 1 that such a movement implies that welfare cannot decrease, and will in fact rise.

The intuition behind this result is simple. Indeed, note that the same level of capacity as the one selected in the benchmark solution without fixed costs is still feasible. If the same capacity level were chosen, the cost structure would be different but the total cost and regional welfare would be identical to the benchmark. However, the change in the cost structure implies that the marginal cost of a unit of additional capacity has decreased. This implies it becomes interesting to add more capacity and realize reductions in travel user costs. As a consequence, regional welfare increases.

Infrastructures which have, for a given total cost, ceteris paribus, a large fixed cost component, are therefore more beneficial to a welfare maximizing region. However, although welfare rises, optimal pricing of the use of the infrastructure does imply that a higher share of fixed costs is likely to decrease the cost recovery ratio. To see this, first note that the cost recovery ratio in the given region is defined as toll revenues relative to capacity costs:

$$
\rho=\frac{\theta Y}{F+k Z}
$$

Now consider optimal pricing and investment behavior by the regional government. In the case of zero through traffic the welfare function (7) reads:

$$
W_{\text {reg }}=\int_{0}^{Y} P^{Y}(y) d y-g^{Y} Y+\theta Y-F-k Z
$$

Maximizing with respect to $\theta$ and $Z$ yields, using the equality between generalized price and generalized cost in equilibrium, the following toll and capacity rules, respectively:

$$
\begin{aligned}
& \theta=C^{\prime} \frac{Y}{Z} \\
& C^{\prime} \frac{Y^{2}}{Z^{2}}=k
\end{aligned}
$$


The optimal toll rule just says that the toll equals the marginal external congestion cost; optimal capacity is obtained when the marginal cost and benefit of extra capacity are equal. Substituting these results in (9) immediately yields:

$$
\rho=\frac{k Z}{F+k Z}
$$

The cost recovery ratio is just the share of variable costs in total capacity costs, a simple application of the general rules derived by Mohring and Harwitz (1962). The ratio equals the elasticity of capacity cost with respect to capacity (see (6)). Although changes in the cost structure obviously affect optimal capacity $Z$ this does suggest that, the higher the importance of fixed costs, the lower the cost recovery ratio, given optimal pricing ${ }^{5}$. This is the basis for financing concerns in policy circles with respect to infrastructure investment involving high fixed costs.

We summarize our findings as Proposition 1 below.

PROPOSITION 1: Assume a linear capacity cost function. Consider a regional government that maximizes regional welfare and faces only local transport demand. Then a higher share of fixed capacity costs along an isocost-isocapacity line: (i) increases regional welfare, but (ii) reduces the cost-recovery ratio.

This proposition implies a dilemma: systems with high fixed costs are, ceteris paribus, welfare-improving but also raise the deficit ${ }^{6}$. The latter phenomenon has been stressed in the cost recovery literature; the former has somewhat been overlooked.

\subsection{The case of a single region with local and through traffic}

In many federal states, a local infrastructure is also used by non residents. However, following the same argument as before, one again easily shows that a higher share of fixed costs can only improve welfare. Indeed, as long as the regional government has full control of the pricing and investment decisions, it can always stick to the policy that was optimal in the case with lower fixed costs; hence, it produces at least the same regional welfare as before. But since the decrease in

\footnotetext{
${ }^{5}$ Taking into account the impact of the cost structure on capacity, one easily shows that the effect of higher fixed costs along an isocost-isocapacity line on the cost recovery ratio is negative if the elasticity of demand with respect to capacity is smaller than one.

${ }^{6}$ Note that the welfare maximizing problem of the regional government implicitly assumes a cost of funds equal to one; no extra weight is given to toll revenues. This implies that as long as only local users make use of the infrastructure and the regional government has access to public funds whose marginal cost is not too far above one, a lower cost recovery ratio is not inconsistent with higher regional welfare.
} 
marginal capacity cost makes extra capacity beneficial, higher capacity will be chosen and welfare rises. The formal proof is provided in Appendix 2.

The presence of through traffic does have important implications for cost recovery. The regional government now has an interest in tax exporting by raising the user charge above the marginal cost (see, e.g., Levinson (2001), De Borger et al. (2007)). The cost recovery ratio is now:

$$
\rho=\frac{\theta(Y+X)}{F+k Z}
$$

The optimal toll and capacity rules that follow from maximizing the objective function (7) can be written as, after simple algebra (also see De Borger et al. (2007)):

$$
\begin{aligned}
& \theta=C^{\prime} \frac{Y}{Z}-\frac{X}{\frac{\partial V}{\partial \theta}} \\
& Y\left\{C^{\prime}\left[V-Z \frac{\partial V}{\partial Z}\right]\right\}+\theta Z^{2} \frac{\partial V}{\partial Z}=k Z^{2}
\end{aligned}
$$

where, as before, $V=X+Y$ is the total transport flow on the regional link. Note that the pricing rule (12) indeed implies tax exporting: the toll is higher than marginal social cost, since the second term on the right hand side is positive and increasing in the importance of through traffic. Optimal capacity sets the net benefit (benefit at constant transport volume due to time savings minus the cost due to induced transport volumes plus extra toll revenues) equal to marginal capacity cost.

Combining (12) and (13) yields, after simple algebra:

$$
C^{\prime} Y(X+Y)=X Z^{2} \frac{\left[\frac{\partial V}{\partial Z}\right]}{\left[\frac{\partial V}{\partial \theta}\right]}+k Z^{2}
$$

Substituting this result into the cost recovery expression (11) leads to:

$$
\rho=\frac{k Z-\frac{X V\left(1-\varepsilon_{Z}\right)}{\frac{\partial V}{\partial \theta}}}{F+k Z}
$$

where $\varepsilon_{Z}$ is the elasticity of total transport demand (local plus through traffic) with respect to capacity increases. So:

$$
\varepsilon_{Z}=\frac{\partial V}{\partial Z} \frac{Z}{V}, \quad V=X+Y
$$


Using (4), it follows that $\varepsilon_{Z}<1$ : a capacity increase raises total transport demand less than proportionately.

Interpretation of (14) is easy. First note that, if there is no through traffic, we have the same rule as in the case of local traffic only (see (10)). Second, the presence of foreign users implies that cost recovery need not be a problem, even for very high fixed costs. The second term in the numerator of (14) suggests that the cost recovery ratio is a rising function of the importance of through traffic. For substantial through traffic levels, (14) suggests that the cost recovery ratio can easily exceed one. Note also that it is now not obvious at all that raising the importance of the fixed cost $F$ will reduce the cost recovery ratio, since all terms in the numerator depend on this share as well.

Note that this result on cost recovery hinges on the assumption of regional authority over pricing the infrastructure. If the region is restricted in its pricing policies, this has obvious implications for cost recovery. To see this, note that the optimal regional toll rule (12) can be rewritten, using (3) and remembering that $V=X+Y$, as:

$$
\theta=C^{\prime} \frac{V}{Z}-X\left[\frac{\frac{\partial P^{X}}{\partial X} \frac{\partial P^{Y}}{\partial Y}}{\frac{\partial P^{X}}{\partial X}+\frac{\partial P^{Y}}{\partial Y}}\right]
$$

The first term on the right hand side is the global marginal external congestion cost, capturing both the time losses of local and through traffic demand. The second term is positive, implying that the toll exceeds the global marginal external cost. Now suppose that a federal authority imposes tolling at the global marginal external cost. This prevents the region from charging its preferred (higher) toll. On the one hand, investment incentives are reduced because of lower benefits of extra capacity investment (see (13)); on the other hand, demand by local users increases due to lower tolls, raising investment incentives. The effects on capacity and cost recovery are a priori unclear.

We summarize the results of this subsection in Proposition 2.

PROPOSITION 2: Assume a linear capacity cost function. Consider a regional government that maximizes regional welfare but faces both local and through traffic demand. Then:

(i) A higher share of fixed capacity costs along an isocost-isocapacity line increases welfare 
(ii) Even for high fixed cost infrastructures, funding problems are unlikely to arise if through traffic demand is substantial and regions can decide autonomously on user charges due to tax exporting behaviour by the regional government.

(iii) Cost recovery may be a problem if regions are restricted in their policies, e.g., if they are restricted to price at marginal social cost

\subsection{Extensions: alternative pricing regimes and multiple competing regions}

The model used in this section was extremely simple. However, the main insights do not change in a qualitative sense when extending the model in various directions.

When showing that higher shares of fixed infrastructure costs were welfareimproving, we assumed uniform tolls throughout. Interestingly, this finding holds quite generally for various alternative pricing instruments as well. Suppose, for example, that different pricing instruments are used that allow toll differentiation between local and through traffic. Alternatively, assume only local transport can be taxed, e.g., because of the use of fuel taxes in a small region. In both cases, welfare increases at higher fixed cost shares, for the same reasons as in Sections 2.1 and 2.2. Interestingly, the proposition even holds when no user charges can be implemented at all, and notwithstanding the fact that through traffic is decreasing the welfare of the local users. The main explanation for the positive welfare effect is, again, that the lower marginal capacity cost increases the optimal capacity level; this also benefits local users.

Cost recovery results, of course, do depend on the pricing instruments used. In the case of toll differentiation, we again find strong tax exporting behavior by the regional government, leading to high cost recovery ratios even in the presence of high fixed capacity cost shares. But, if for some reason only local demand can be tolled then cost recovery is indeed a problem.

We also can extend the model to a setting of a transport corridor that passes through several regions, where we allow for tax and capacity competition between the regions (as in De Borger et al. (2007)). Again, this does not change the basic insight that a higher fixed cost share of capacity raises regional welfare. Tax competition between the regions does imply that toll levels are reduced compared to the case analyzed in Section 2.2 above, due to reactions of the other regions. A toll increase in a given region along a transport corridor will lead the other regions to react by somewhat reducing toll levels. 
To elaborate on the case of a transport corridor with competing regions, first consider the simplified case without tolling. In Appendix 3, we show the following proposition:

\section{Proposition 3:}

Assume linear demand, user cost and capacity cost functions, and consider a capacity game between two regional governments that each maximize regional welfare; both regions face local and through traffic. Comparing cost structures along an isocost and isocapacity line then imply that the welfare effect of a higher share of fixed costs is theoretically ambiguous. Under plausible conditions, however, it is positive.

The reason for the ambiguity in general is that the cost structure affects welfare in two different ways. First, as in the case of a single region, a higher share of fixed costs in a region raises local welfare, conditional on capacity investment in the other region. Second, however, in a Nash capacity game the cost structure in one region implies strategic responses by the other region. These were obviously absent in the analysis with only one region. Capacity cost changes in A affect optimal capacity in A and, hence, strategic reactions for optimal capacity in B. Depending on the size of these strategic effects and the slope of capacity reaction functions, this second effect may strengthen or weaken the direct welfare-enhancing effect of higher fixed costs.

If we consider the impact of cost structure changes in the full capacity-tolling game between the two countries, the theoretical analysis becomes highly intractable. We resort to numerical analysis in section 3 to learn more about the role of fixed capacity costs on capacities, tolls and welfare.

Finally, we could also generalize the linear capacity cost functions to more general non-linear forms. The isocost-isocapacity locus concept can be generalized to any non linear capacity function, introducing any number of parameters for the non linear cost function. For the basic intuition that moving to a higher fixed cost share function is beneficial to hold, one needs that along the locus, an increase in the fixed cost share is compensated by a decrease in the marginal capacity cost.

\subsection{The capacity cost structure and the selection of investment projects by regions}


The suggestion that a capacity cost structure with a high share of fixed costs is a good thing for the regions' welfare has still other important implications, provided one is willing to interpret different cost structures in a slightly different way. Let us interpret different combinations $(F, k)$ as reflecting different investment 'projects', assuming one of many different projects could be executed. For example, various rail and road investment projects may be characterized by very different proportions of fixed and variable capacity cost shares. Moreover, let us say that a project is beneficial from a global or federal perspective if it generates positive total (extra) welfare for local and through traffic users together; a project is beneficial for the region where the investment takes place if it generates positive extra regional welfare. A corollary of the propositions in the previous subsections is then the region is more inclined to select federally interesting projects the higher the share of fixed costs. Moreover, several straightforward results on the effect of tolling immediately follow.

To see this, assume that a region A will only undertake projects for which the welfare contribution, denoted $\mathrm{W}_{\mathrm{A}}$, is positive: $W_{A}\left(\theta_{A}, Z_{A} ; k, F\right) \geq 0$ where the policy variables indexed by A stand for the choices made by the regional government. Suppose that the project also benefits foreign users; the surplus of these users is captured by $W_{T}\left(\theta_{A}, Z_{A} ; k, F\right)$, assumed to be positive. As regional governments do not take into account the consumer surplus of these foreign users, this may imply that some projects that are beneficial for the "federation" as a whole (projects for which $\left.W_{A}\left(\theta_{A}, Z_{A} ; k, F\right)+W_{T}\left(\theta_{A}, Z_{A} ; k, F\right) \geq 0\right)$ are not undertaken by the individual region. However, since $\mathrm{W}_{\mathrm{A}}$ is an increasing function of the share of fixed costs (as shown in the previous section) and assuming that through traffic welfare is positive, it follows that, along an isocost and isocapacity locus, the higher is the level of fixed costs, the higher is the probability that a regional government undertakes a federally beneficial project. The policy implication of this finding is clear, viz., that federal support for regional projects becomes less (and not more) necessary when the share of fixed costs rises.

The above discussion can easily be extended to derive several interesting propositions on the effect of tolling on the willingness of an individual region to execute federally beneficial projects. Again denote by $W_{A}\left(\theta_{A}, Z_{A} ; F, k\right)$ the maximum welfare region A achieves for a given cost structure and the optimal toll selected by 
the region. Similarly, let $W_{A}\left(\theta_{F B}, Z{ }_{A} ; F, k\right)$ be the maximum welfare attainable for the given cost structure and first-best optimal tolls (marginal social cost pricing imposed by the federal level). The capacity $Z_{A}^{\prime}$ is the capacity chosen by the region given that tolls have to be at marginal social cost, as required by the federal authorities. We further denote $W_{T}\left(\theta_{A}, Z_{A} ; F, k\right)$ and $W_{T}\left(\theta_{F B}, Z_{A}{ }_{A} ; F, k\right)$ as the corresponding welfare levels for the through traffic users. Finally, $W_{A}\left(Z_{A}^{*} ; F, k\right), W_{T}\left(Z_{A}^{*} ; F, k\right)$ are the welfare levels in region A and for through traffic users in the absence of tolling; the corresponding capacity level is then $Z_{A} *$.

Now note the following relations. First, both $W_{A}\left(\theta_{A}, Z_{A} ; F, k\right)$ and $W_{T}\left(\theta_{A}, Z_{A} ; F, k\right)$ are increasing in $\mathrm{F}$ along an isocost-isocapacity line. Second, a region cannot be worse off if it has access to tolling compared to the case without tolls, so that

$$
W_{A}\left(Z_{A}^{*} ; F, k\right)<W_{A}\left(\theta_{A}, Z_{A} ; F, k\right)
$$

Third, by definition of first-best pricing, it is the case that:

$$
W_{A}\left(\theta_{A}, Z_{A} ; F, k\right)+W_{T}\left(\theta_{A}, Z_{A} ; F, k\right)<W_{A}\left(\theta_{F B}, Z_{A}{ }_{A} ; F, k\right)+W_{T}\left(\theta_{F B}, Z^{\prime}{ }_{A} ; F, k\right)
$$

Using these relations, we easily show that allowing a region or region to decide on tolls in the region raises the number of federally beneficial projects that the region will autonomously want to execute. This directly follows from the finding that tolling raises regional welfare. Moreover, it also follows that imposing marginal social cost pricing on the region raises overall welfare but decreases the number of federally beneficial projects that the region will want to execute. This statement follows because first-best tolls must necessarily reduce regional welfare compared to regionally optimal tolls.

We summarize our finding from this subsection in the following proposition.

PROPOSITION 4: In a region facing both local and through traffic demand: the more likely a region is to execute a federally beneficial project. Starting from a no tolling equilibrium, allowing uniform tolling implies that more projects that are worthwhile from the federal viewpoint will be regionally implemented.

(iii) Starting from a uniform tolling equilibrium decided by a regional government, imposing first-best tolls on regions improves federal welfare, but it decreases the number a projects taken on by an individual region. 


\section{Numerical illustration}

In this section we look at the effect of increasing fixed costs and decreasing variable costs on pricing, capacity investment, taxes, demand, welfare and cost recovery. After briefly discussing calibration of the model, we first consider the situation when there is only local traffic. Both the case with and without tolling is considered. Then we introduce through traffic and analyze the changes this implies; again, the case with and without tolling are considered. In a final subsection, we report on the results of other tolling regimes and multiple competing regions.

For the numerical application we use linear demand and user cost specifications. We prefer the linear demand function because we want a choke price above which demand drops to zero ${ }^{7}$. A linear user cost function is used for purposes of analytical tractability; moreover, it can be formally justified in a bottleneck type of congestion model (Arnott, de Palma, Lindsey (1993)). Specifically, we use the following demand and user cost functions:

$$
\begin{aligned}
& P^{Y}=c-d Y \\
& P^{X}=a-b X \\
& C=\alpha+\beta q=\alpha+\beta \frac{V}{Z}
\end{aligned}
$$

\subsection{Calibration}

We will study the implications of the capacity cost structure for different regimes: with and without through traffic, with and without tolling, etc. For all regimes considered, we start with the same constant returns to scale capacity cost function $C(Z)=k Z$; hence, $k$ was taken to be the same for all regimes. The variable capacity cost $k$ was calibrated in De Borger et al. (2007) such that, in the no-toll reference equilibrium, local and through traffic demand each account for $50 \%$ of total traffic in the region studied, and that the share of other costs and time costs are equal. Moreover, the demand elasticities equal -0.31 for local traffic and -0.13 for through traffic $^{8}$. The calibrated unit (variable) cost of capacity was equal to $€ 18.69$. This value was used for all regimes studied in this paper as well.

\footnotetext{
${ }^{7}$ A simple alternative is a constant elasticity demand function, but this implies an infinite willingness to pay for very low quantities so that the transport service is always provided.

${ }^{8}$ The parameters used are $a=567,114 ; b=0,3356 ; c=283,557 ; d=0,1677 ; \alpha=34,335 ; \beta=23,924$.
} 
For each regime, we then proceeded as follows. Starting from the constant returns to scale situation, i.e., using $k_{0}=€ 18.69$ and $F_{0}=0$, we determined the optimal $Z^{*}$ and the associated total cost $C\left(Z^{*}\right)$ for this regime. We then allow the variable capacity cost to decrease and, simultaneously, the fixed cost to increase in such a way that, for a given $Z^{*}$, the total cost, $C\left(Z^{*}\right)$, remains constant. Note that this defines the isocost-isocapacity line for the regime under consideration. Of course, the isocostisocapacity line differs between regimes because the optimal capacity level $Z^{*}$, and hence the total cost, depend on whether tolling is possible and whether through traffic is present.

\subsection{Effects of the capacity cost structure: The case of a single region without through}

traffic

We first look at the effect on the investment decisions of a given region when the variable component of capacity cost decreases and the fixed component increases and there is no possibility of through traffic. The results of varying the share of fixed and variable capacity costs are presented in Tables 1a (tolls are used) and 1b (no tolls), as well as in Figure 2.

Consider Table 1a. The first two lines show some $(k, F)$ pairs along the isocostisocapacity line, determined as described above. To be more precise, all these variable and fixed cost pairs produce, for the optimal capacity under constant returns to scale (which equals $Z^{*}=1395$ for this regime), the same total capacity cost (equal to $\left.C\left(Z^{*}\right)=26080\right)$. The rest of the table gives, among others, the impact on demand, tolls, capacity levels and welfare. Results are easily interpreted. First note that optimal capacity provision rises when the fixed cost component increases. This is quite intuitive, due to the smaller marginal cost of capacity expansion. Higher capacity further implies lower congestion. Tolls on transport use, which are equal to the local marginal external costs (see the theoretical section 2.1), also reduce markedly due to the large decrease in congestion. The increase in demand is relatively small.

As expected, the degree of returns to scale has implications for the relation between toll revenues and total capacity costs. The latter have risen because of much higher capacity investments. Toll revenues go down when fixed capacity costs become more important, due to substantially lower tolls on just slightly more demand. 
Cost recovery becomes therefore less favorable. This is as predicted by the theory. Figure 2 represents the results for this case graphically.

In Table 1b, we report the results in the case the region for some reason cannot or does not want to use tolls, and only determines investment optimally. The results are very similar in all relevant respect to those of Table 1a, except of course for demand levels; these are higher due to the absence of tolls.

\begin{tabular}{|l|r|r|r|r|r|r|r|}
\hline $\mathrm{k}$ & 18.69 & 16.82 & 14.95 & 9.35 & 5.61 & 3.74 & 1.87 \\
\hline $\mathrm{F}$ & 0 & 2608 & 5216 & 13040 & 18256 & 20864 & 23472 \\
\hline \hline$\theta$ & 21.15 & 20.06 & 18.91 & 14.95 & 11.58 & 9.46 & 6.69 \\
\hline $\mathrm{Y}$ & 1233 & 1246 & 1260 & 1307 & 1347 & 1373 & 1406 \\
\hline $\mathrm{Z}$ & 1395 & 1486 & 1594 & 2091 & 2783 & 3472 & 5029 \\
\hline $\mathrm{C}(\mathrm{Z})$ & 26080 & 27609 & 29046 & 32585 & 33861 & 33845 & 32872 \\
\hline Toll revenue & 26080 & 25001 & 23830 & 19545 & 15605 & 12981 & 9400 \\
\hline Cost recovery & 1.0 & 0.9 & 0.8 & 0.6 & 0.5 & 0.4 & 0.3 \\
\hline W region & 127602 & 127685 & 127952 & 130297 & 134027 & 137200 & 142288 \\
\hline & & & & & & & \\
\hline
\end{tabular}

Table 1a: Single region, effect of changes in the cost structure (tolls, no through traffic)

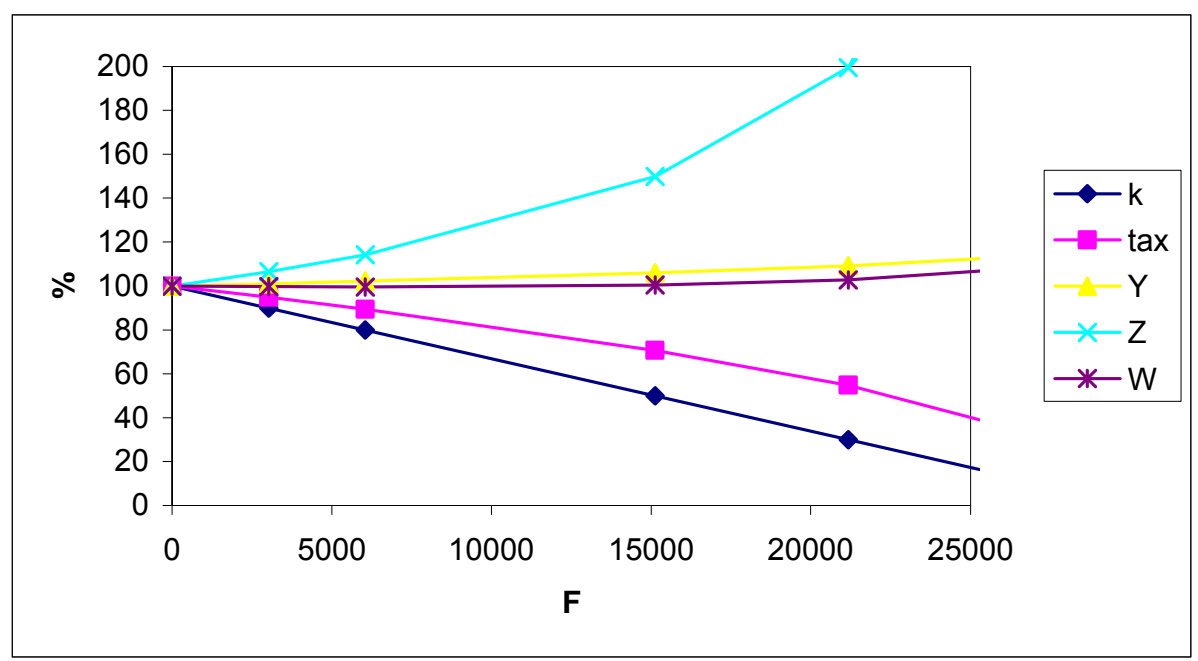

Figure 2: Percentage changes in key parameters as a function of fixed (and variable) capacity costs with no through traffic 


\begin{tabular}{|l|r|r|r|r|r|r|r|}
\hline $\mathrm{k}$ & 18.69 & 16.82 & 14.95 & 9.35 & 5.61 & 3.74 & 1.87 \\
\hline $\mathrm{F}$ & 0 & 2608 & 5216 & 13040 & 18256 & 20864 & 23472 \\
\hline $\mathrm{Y}$ & 1353 & 1360 & 1368 & 1393 & 1415 & 1428 & 1445 \\
\hline $\mathrm{Z}$ & 1461 & 1553 & 1660 & 2159 & 2852 & 3542 & 5099 \\
\hline $\mathrm{C}(\mathrm{Z})$ & 27317 & 28727 & 30044 & 33219 & 34246 & 34104 & 33002 \\
\hline W region & 126332 & 126538 & 126930 & 129652 & 133637 & 136939 & 142156 \\
\hline & & & & & & & \\
\hline
\end{tabular}

Table 1b: Single region, effect of changes in the cost structure (no tolls, no through traffic)

\subsection{Case of a single region with through traffic}

Tables $2 \mathrm{a}-2 \mathrm{~b}$ report the results when through traffic is present. In the reference case used for calibration, it is assumed that through traffic accounts for $50 \%$ of total traffic in the absence of tolls. Note that, as explained above, the $(k, F)$ pairs differ from those in table 1 , because this regime produces a different optimal capacity and optimal capacity cost under constant returns to scale capacity expansion.

Apart from toll levels and cost recovery, the results are again quite similar for the cases with and without tolling. As before, decreasing the size of the variable capacity costs raises optimal capacity levels, and welfare rises. There is also a marked increase in investment in capacity whereas both local and through traffic demands increase only slightly.

The crucial difference between Tables $2 \mathrm{a}$ and 1a obviously relates to tolling behaviour and cost recovery. Tax exporting implies that the uniform toll in Table $2 \mathrm{a}$ is very high. Moreover, contrary to the case without through traffic, it only marginally declines for higher shares of fixed capacity costs. To understand this, remember that the optimal uniform toll consists of two components (see (12)), viz., the local marginal external cost and a tax exporting component that depends on the importance of through traffic and the sensitivity of demand. The local marginal external cost slightly declines when fixed capacity costs are more prominent (due to lower volumecapacity ratios), which reduces the toll. The tax exporting component, however, slightly increases due to higher through traffic demand.

Considering the cost recovery issue note that, unlike in the case without through traffic, tax exporting implies that the uniform tolls generate much more revenues than required to finance capacity costs. Funding is not a problem at all, 
given that the region decides on tolling (and hence charges high tolls) and investment levels. Note also that cost recovery ratios do not monotonically decline when fixed costs become more important.

Comparing the welfare effects reported in the bottom rows of Tables $1 \mathrm{a}$ and $2 \mathrm{a}$ suggests that, in the case tolling is possible, the presence of through traffic is likely to raise welfare. Note that the regions' welfare in the case of zero through traffic amounts to 127602 at the reference case with zero fixed costs; welfare with through traffic amounts to 217217 , reflecting huge transport tax revenues. ${ }^{9}$ However, when through traffic cannot be tolled (compare Table $1 \mathrm{~b}$ and $2 \mathrm{~b}$ ), adding through traffic flows reduces welfare. It amounts to 126332 without through traffic (zero fixed cost case) versus 101681 when through traffic, which can't be tolled, is introduced.

\begin{tabular}{|l|r|r|r|r|r|r|}
\hline $\mathrm{k}$ & 18.69 & 16.82 & 14.95 & 9.35 & 5.61 & 1.87 \\
\hline $\mathrm{F}$ & 0 & 3381 & 6761 & 16904 & 23665 & 30426 \\
\hline$\theta$ & 143.77 & 143.23 & 142.65 & 140.67 & 138.99 & 136.54 \\
\hline $\mathrm{Y}$ & 502 & 512 & 522 & 558 & 588 & 632 \\
\hline $\mathrm{X}$ & 1096 & 1101 & 1106 & 1124 & 1139 & 1161 \\
\hline $\mathrm{Z}$ & 1809 & 1924 & 2060 & 2691 & 3567 & 6413 \\
\hline $\mathrm{C}(\mathrm{Z})$ & 33807 & 35745 & 37566 & 42051 & 43667 & 42414 \\
\hline Toll revenue & 229843 & 231060 & 232329 & 236576 & 240024 & 244760 \\
\hline Cost recovery & 6.8 & 6.5 & 6.2 & 5.6 & 5.5 & 5.8 \\
\hline Welfare region & 217217 & 217322 & 217661 & 220632 & 225359 & 235827 \\
\hline Through traffic welfare & 201633 & 203421 & 205321 & 211946 & 217667 & 226110 \\
\hline Total welfare & 418850 & 420743 & 422981 & 432578 & 443025 & 461937 \\
\hline
\end{tabular}

Table 2a: Single region with local and through traffic demand (uniform toll)

\begin{tabular}{|l|r|r|r|r|r|r|}
\hline $\mathrm{k}$ & 18.69 & 16.82 & 14.95 & 9.35 & 5.61 & 1.87 \\
\hline $\mathrm{F}$ & 0 & 3381 & 6761 & 16904 & 23665 & 30426 \\
\hline $\mathrm{Y}$ & 1291 & 1302 & 1313 & 1351 & 1382 & 1427 \\
\hline $\mathrm{X}$ & 1490 & 1496 & 1501 & 1520 & 1536 & 1558 \\
\hline $\mathrm{Z}$ & 2011 & 2171 & 2327 & 3046 & 4043 & 7278 \\
\hline $\mathrm{C}(\mathrm{Z})$ & 37239 & 39906 & 41555 & 45372 & 46339 & 44030 \\
\hline Welfare region & 101681 & 102232 & 103051 & 107738 & 113992 & 126773 \\
\hline Through traffic welfare & 279604 & 284276 & 289212 & 306220 & 320661 & 341605 \\
\hline Total welfare & 381285 & 386509 & 392263 & 413958 & 434653 & 468378 \\
\hline
\end{tabular}

Table 2b: Single region with local and through traffic demand (No tolls)

${ }^{9}$ Total welfare (including the welfare of through traffic users) in the tables is calculated on the basis of (8). 
To conclude this subsection, we briefly compare the results with the first-best 'global' optimum, i.e., the optimal pricing and investment policy that does take account of the welfare of through traffic users when making decisions; this optimum is derived from objective function (8). One easily shows that this implies setting tolls

at the global marginal external congestion cost (which equals $C^{\prime} \frac{V}{Z}$ ) that captures both locals and through traffic time losses. The numerical results (not reported) again show that capacities and welfare are both rising when the share of the fixed cost becomes more important. Not surprisingly, cost recovery associated with optimal behaviour at the federal level is again problematic when there are fixed infrastructure costs.

Together with the results in Table 2a, this illustrates again the dilemma for federal authorities. When there are high fixed costs, toll-capacity setting by regions does not pose serious funding problems but, of course, global welfare is lower than at the global optimum. The latter, however, implies less than full cost recovery and hence funding problems. If there are fixed costs, the trade-off is clear. The 'federal' level can impose efficient pricing and investment but then needs to support funding, or it can allow regions to toll through traffic. This implies funding is no problem but results in welfare losses at the federal level.

\subsection{The role of fixed capacity costs in a serial transport corridor.}

In this sub-section we finally briefly report on application of some extended models. We studied alternative pricing instruments together with tax competition in a serial transport corridor with two regions. In a serial transport corridor, through traffic passes through two regions that each have also local traffic on their network. Both regions play a game in capacity and tolling (see De Borger et al. (2007)). Next to uniform tolling and no tolling we study two more pricing regimes: differentiated tolls for local and through traffic and a regime where only local users can be tolled. The results that are reported are highly intuitive and do not change the main insights from this paper; for example, in all cases we found higher fixed cost shares to increase welfare and to raise capacity.

The results are presented in Tables $3 \mathrm{a}$ to $3 \mathrm{~d}$ and in Figures 3 to 6 below. A number of trends are common to all the results. Decreasing the size of the variable capacity costs raises optimal capacity levels, independent of the tolling regime. 
Welfare rises in all cases as well. The welfare is in fact positive in all cases but is highest with differentiated tolling, where tax revenue can be extracted from foreign traffic, and lowest with no toll.

In the regimes with differentiated tolling and local tolls only we observe a large decrease in the local toll, as local marginal external costs decrease in line with congestion. The through traffic toll rises slightly. For the uniform toll regime, the toll marginally declines. To understand this, note that the optimal uniform toll consists of two components (see De Borger et al (2007)), viz., the local marginal external cost and a tax exporting component that depends on the importance of through traffic and the sensitivity of demand. The second component is numerically most important. The local marginal external cost declines when fixed capacity costs are more prominent, which reduces the toll. The second component, however, increases. This leads to the resulting small decrease in tax in this case. 


\begin{tabular}{|l|r|r|r|r|r|r|}
\hline $\mathrm{k}$ & 18.69 & 16.82 & 14.95 & 9.35 & 5.61 & 1.87 \\
\hline $\mathrm{F}$ & 0 & 3025 & 6050 & 15125 & 21176 & 27226 \\
\hline$\theta_{\mathrm{A}}$ & 104.67 & 104.42 & 104.15 & 103.23 & 102.44 & 101.29 \\
\hline $\mathrm{Y}_{\mathrm{A}}$ & 732 & 741 & 749 & 779 & 804 & 841 \\
\hline $\mathrm{X}$ & 732 & 741 & 749 & 779 & 804 & 841 \\
\hline $\mathrm{ZA}$ & 1618 & 1724 & 1849 & 2428 & 3233 & 5847 \\
\hline $\mathrm{C}(\mathrm{Z})$ & 30251 & 32030 & 33701 & 37819 & 39304 & 38154 \\
\hline Tax revenue & 153333 & 154652 & 156039 & 160764 & 164706 & 170301 \\
\hline Cost recovery & 5.1 & 4.8 & 4.6 & 4.3 & 4.2 & 4.5 \\
\hline Welfare region & 168093 & 168631 & 169414 & 173809 & 179617 & 191439 \\
\hline Through traffic welfare & 90023 & 92017 & 94152 & 101729 & 108430 & 118584 \\
\hline Total welfare & 426209 & 429279 & 432979 & 449348 & 467664 & 501462 \\
\hline
\end{tabular}

Table 4a: Serial corridor with local and through traffic (uniform toll, capacity-toll competition)

\begin{tabular}{|l|r|r|r|r|r|r|}
\hline $\mathrm{k}$ & 18.69 & 16.82 & 14.95 & 9.35 & 5.61 & 1.87 \\
\hline $\mathrm{F}$ & 0 & 3025 & 6050 & 15125 & 21176 & 27226 \\
\hline $\mathrm{t}_{\mathrm{A}}$ & 22.32 & 21.19 & 19.99 & 15.85 & 12.30 & 7.12 \\
\hline $\mathrm{T}_{\mathrm{A}}$ & 160.39 & 160.70 & 161.01 & 162.10 & 163.02 & 164.35 \\
\hline $\mathrm{Y}_{\mathrm{A}}$ & 1219 & 1233 & 1247 & 1296 & 1339 & 1400 \\
\hline $\mathrm{X}$ & 396 & 401 & 407 & 425 & 440 & 463 \\
\hline $\mathrm{ZA}$ & 1732 & 1845 & 1979 & 2599 & 3461 & 6261 \\
\hline $\mathrm{C}(\mathrm{Z})$ & 32371 & 34063 & 35641 & 39414 & 40582 & 38929 \\
\hline Tax revenue & 90793 & 90614 & 90395 & 89404 & 88268 & 86132 \\
\hline Cost recovery & 2.8 & 2.7 & 2.5 & 2.3 & 2.2 & 2.2 \\
\hline Welfare region & 183147 & 184048 & 185220 & 191003 & 198044 & 211743 \\
\hline Through traffic welfare & 26363 & 27025 & 27736 & 30277 & 32549 & 36028 \\
\hline Total welfare & 392658 & 395121 & 398176 & 412284 & 428636 & 459514 \\
\hline
\end{tabular}

Table 4b: Serial corridor with local and through traffic (differentiated tolls, capacity-toll competition)

\begin{tabular}{|l|r|r|r|r|r|r|}
\hline $\mathrm{k}$ & 18.69 & 16.82 & 14.95 & 9.35 & 5.61 & 1.87 \\
\hline $\mathrm{F}$ & 0 & 3025 & 6050 & 15125 & 21176 & 27226 \\
\hline $\mathrm{t}_{\mathrm{A}}$ & 14.43 & 13.72 & 12.97 & 10.33 & 8.04 & 4.68 \\
\hline $\mathrm{Y}_{\mathrm{A}}$ & 1215 & 1229 & 1244 & 1295 & 1338 & 1401 \\
\hline $\mathrm{X}$ & 1301 & 1311 & 1321 & 1356 & 1386 & 1428 \\
\hline $\mathrm{ZA}$ & 1945 & 2073 & 2226 & 2930 & 3909 & 7086 \\
\hline $\mathrm{C}(\mathrm{Z})$ & 36346 & 37904 & 39330 & 42512 & 43096 & 40471 \\
\hline Tax revenue & 17536 & 16865 & 16127 & 13370 & 10764 & 6557 \\
\hline Cost recovery & 0.5 & 0.4 & 0.4 & 0.3 & 0.2 & 0.2 \\
\hline Welfare region & 105005 & 105659 & 106575 & 111509 & 117869 & 130641 \\
\hline Through traffic welfare & 283945 & 288248 & 292812 & 308677 & 322315 & 342356 \\
\hline Total welfare & 493956 & 499566 & 505961 & 531695 & 558054 & 603639 \\
\hline
\end{tabular}

Table 4c: Serial corridor with local and through demand (local toll only, capacity-toll competition) 


\begin{tabular}{|l|r|r|r|r|r|r|}
\hline $\mathrm{k}$ & 18.69 & 16.82 & 14.95 & 9.35 & 5.61 & 1.87 \\
\hline $\mathrm{F}$ & 0 & 3025 & 6050 & 15125 & 21176 & 27226 \\
\hline $\mathrm{Y}_{\mathrm{A}}$ & 1300 & 1310 & 1320 & 1356 & 1386 & 1428 \\
\hline $\mathrm{X}$ & 1300 & 1310 & 1320 & 1356 & 1386 & 1428 \\
\hline $\mathrm{Z}$ & 2000 & 2129 & 2281 & 2986 & 3965 & 7142 \\
\hline $\mathrm{C}(\mathrm{Z})$ & 37383 & 38837 & 40159 & 43030 & 43407 & 40575 \\
\hline Welfare region & 104395 & 105107 & 106082 & 111195 & 117678 & 130577 \\
\hline Through traffic welfare & 283557 & 287888 & 292481 & 308451 & 322170 & 342303 \\
\hline Total welfare & 492348 & 498103 & 504645 & 530842 & 557527 & 603456 \\
\hline
\end{tabular}

Table 4d: Serial corridor with local and through traffic

(No tolls, capacity competition)

As in the case without through traffic, there is also a marked increase in investment in capacity whereas both local and through traffic increase only slightly. Although relative increases in capacity are similar for all pricing regimes, in absolute terms there is greater investment in capacity when no pricing instruments are available or through traffic cannot be tolled. There is less investment with uniform tolls than with differentiated tolls because further investment would not bring additional revenue from through traffic as this would also penalise local users.

Considering the cost recovery issue note, unlike in the case without through traffic, the uniform (Table 3a) and differentiated tolling (Table 3b) cases generate more revenues than required to finance capacity costs. Note, however, that (contrary to expectations), cost recovery is apparently easiest with uniform tolls. Moreover, cost recovery ratios do not monotonically decline when fixed costs become more important (again, contrary to expectations). When only local tolls (Table 3c) can be used, a substantial deficit occurs; it rises in the share of fixed costs, as predicted by the theory. These results show that funding of infrastructure is hardly a problem in tax-capacity games as long as countries are allowed to toll through traffic. However, it again points at a dilemma: financing of investment is not a problem in this case, but allowing countries to toll through traffic is not welfare improving (also see below, federal solution).

The welfare effects reported in Tables 1,2 and 3 can be interpreted also in a slightly different way. They show that in the cases where through traffic can be tolled (uniform and differentiated tolling cases) the introduction of through traffic is likely to raise welfare. However, when through traffic cannot be tolled, we expect welfare to go down if through traffic is introduced. For example, compare the welfare levels in Table 1a and Tables $3 \mathrm{a}$ and $3 \mathrm{~b}$. The introduction of through traffic combined with 
tolls raises welfare. Now compare Table $1 \mathrm{a}$ with Tables $3 \mathrm{c}$ and $3 \mathrm{~d}$. Introducing non tolled through traffic reduces welfare.

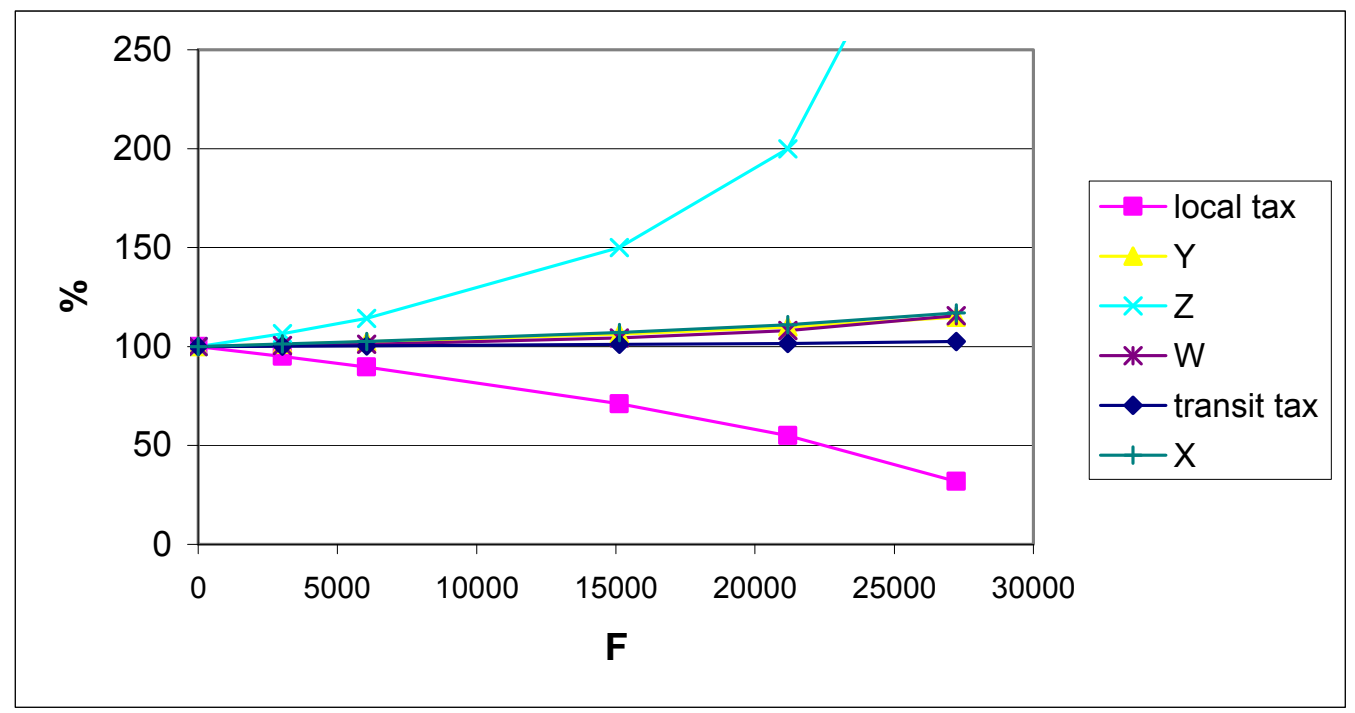

Figure 3: Percentage changes in key parameters as a function of fixed (and variable) capacity costs with differentiated toll, serial transport corridor case

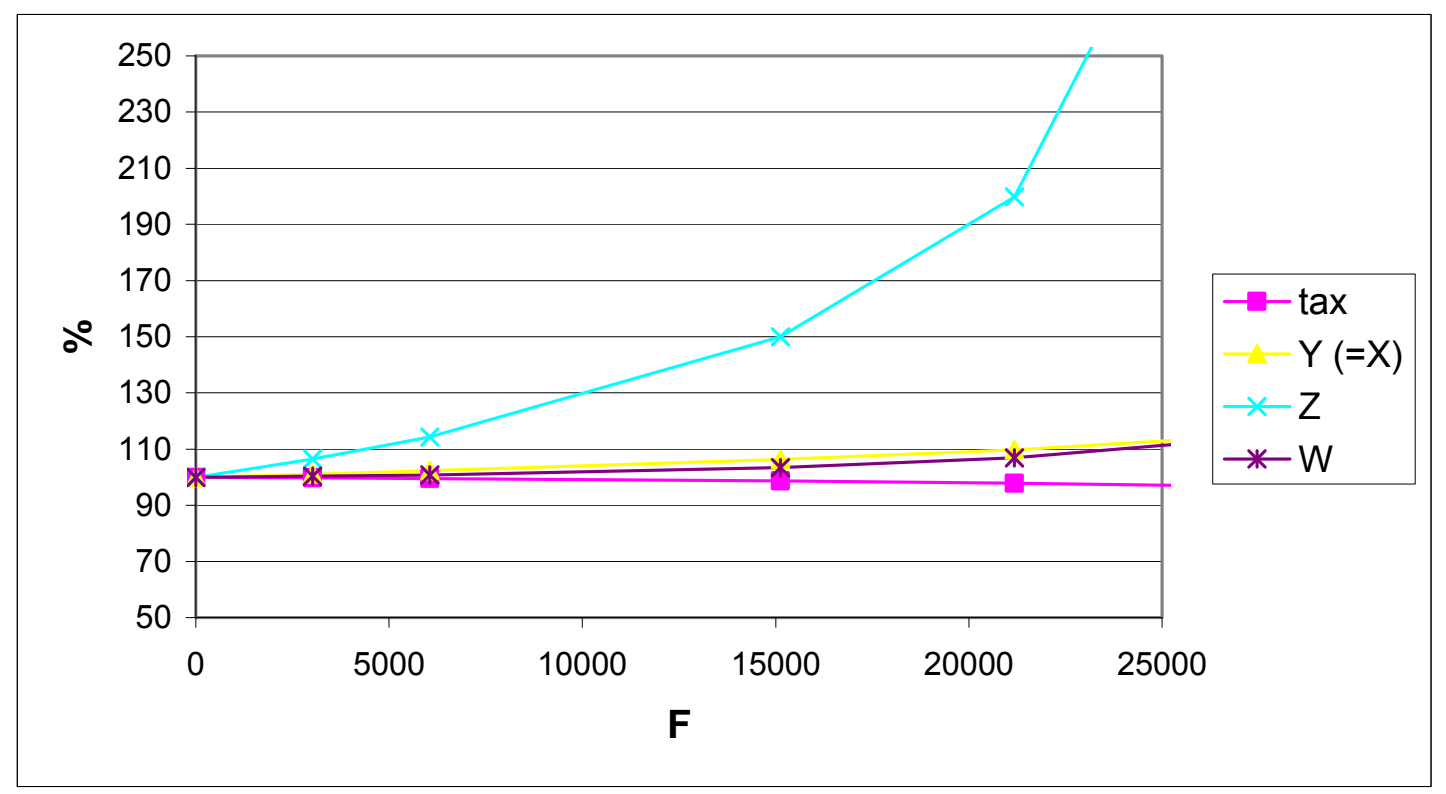

Figure 4: Percentage changes in key parameters as a function of fixed (and variable) capacity costs with uniform toll, serial transport corridor case 


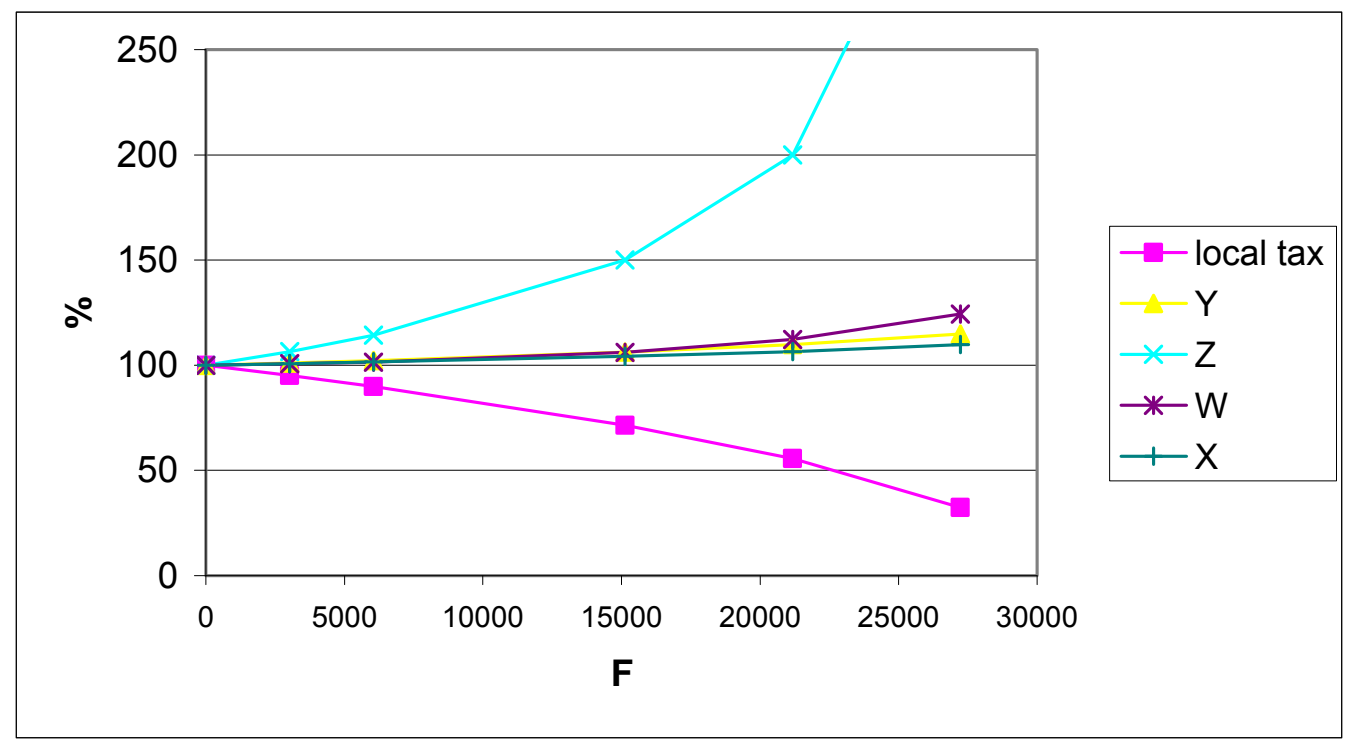

Figure 5: Percentage changes in key parameters as a function of fixed (and variable) capacity costs with local only toll, serial transport corridor case

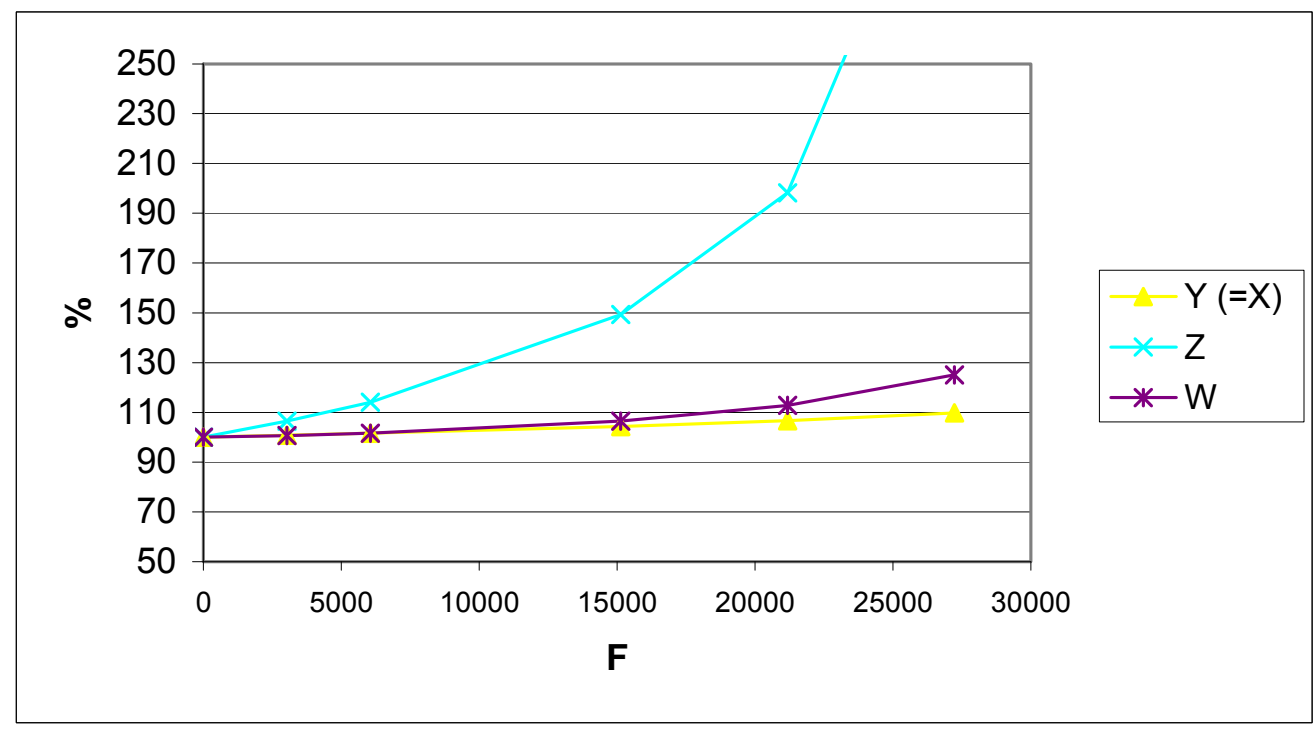

Figure 6: Percentage changes in key parameters as a function of fixed (and variable) capacity costs with no toll, serial transport corridor case 
Finally, in Table 4 we present the 'federal' solution to the two region serial corridor price-capacity problem. This implies uniform tolls equal to the global marginal external cost (taking into account time losses imposed on through traffic). Again, capacity and welfare is rising in fixed cost; cost recovery declines in fixed cost. Obviously, cost recovery associated with optimal behaviour at the federal level is again problematic when there are fixed infrastructure costs. Together with the results in Table 3, these findings illustrate again the dilemma for federal authorities. Even when there are high fixed costs, toll-capacity competition does not pose serious funding problems as long as through traffic can be tolled; however, toll-capacity competition is welfare-reducing. To solve funding problems, two options are open. If there are fixed costs, the federal level can impose efficient pricing and investment but then needs support funding, or it can allow regions to toll through traffic. This implies funding is no problem but results in welfare losses at the federal level.

\begin{tabular}{|l|r|r|r|r|r|r|}
\hline $\mathrm{k}$ & 18.69 & 16.82 & 14.95 & 9.35 & 3.74 & 1.87 \\
\hline $\mathrm{F}$ & 0 & 3025 & 6050 & 15125 & 24201 & 27226 \\
\hline$\theta_{\mathrm{A}}$ & 21.15 & 20.06 & 18.91 & 14.95 & 9.46 & 6.69 \\
\hline $\mathrm{Y}_{\mathrm{A}}$ & 1233 & 1246 & 1260 & 1307 & 1373 & 1406 \\
\hline $\mathrm{X}$ & 1233 & 1246 & 1260 & 1307 & 1373 & 1406 \\
\hline $\mathrm{ZA}$ & 2791 & 2972 & 3187 & 4183 & 6945 & 10058 \\
\hline $\mathrm{C}(\mathrm{Z})$ & 52160 & 53027 & 53710 & 54216 & 50163 & 46025 \\
\hline Tax revenue & 52160 & 50002 & 47660 & 39091 & 25962 & 18800 \\
\hline Cost recovery & 1.0 & 0.9 & 0.9 & 0.7 & 0.5 & 0.4 \\
\hline Welfare region & 127602 & 127268 & 127118 & 128211 & 133864 & 138534 \\
\hline Through traffic welfare & 255204 & 260586 & 266337 & 286674 & 316129 & 331520 \\
\hline Total welfare & 510409 & 515121 & 520573 & 543096 & 583856 & 608588 \\
\hline
\end{tabular}

Table 4. The federal solution

\section{Conclusions}

In this paper we ask what the implications are for welfare and for cost recovery when governments decide on capacity investment and user charges for a transport infrastructure that implies large fixed capacity costs. We obtain some interesting results. First, we show that an infrastructure that has ceteris paribus a higher share of fixed costs raises welfare for the regional government building it. This implies that it increases (and not reduces) the incentives for the regional government 
to invest in it so that it requires less (rather than more) federal subsidies. This holds both in the case the infrastructure is only used by local inhabitants and in the case a region faces a lot of through traffic. Second, we find that, even for capacity characterized by very high shares of fixed costs, financing of infrastructure is generally not an important issue as long as regions are allowed to toll through traffic . Third, if member states cannot toll through traffic, or if a federal authority (such as the EU or the federal level in the USA) can impose pricing at the global marginal social cost, our analysis shows that this reduces investment incentives for the individual regions, and subsidies may be needed.

The difficulty of cost recovery and the associated funding problems in the case of high fixed costs largely explain recent EU policy to focus subsidies much more on rail and inland waterway investments (infrastructure with high fixed costs) than on road. Our results suggest that the emphasis on infrastructures with high fixed capacity costs may be inappropriate. Moreover, our results suggest that the EU should not necessarily subsidize the provision of infrastructure if tolling can be decided by the member states, because cost recovery will typically not be a problem. Finally, the analysis of this paper clearly identifies a dilemma for a federal authority: either one allows countries to decide on tolling and avoids funding problems, but at the expense of lower global welfare, or one imposes optimal tolling from the federal perspective on the regions, but at the expense of lower investment incentives at the regional level. 


\section{References}

Arnott R., de Palma A., Lindsey, 1993, A Structural Model of Peak-Period Congestion: A Traffic Bottleneck with Elastic Demand, American Economic Review 83(1), 161-179

Arnott, R. and M. Kraus, 1995, Financing capacity in the bottleneck model, Journal of Urban Economics 38, 272-290.

Arnott, R. and M. Kraus, 1998, Self-financing of congestible facilities in a growing economy, in Pines, D., E. Sadka and I. Zicha (Eds.), Topics in Public Economics: Theoretical and Applied Analysis, Cambridge University Press, 161-184.

De Borger, B., Proost, S. and K. Van Dender, 2005, Congestion and tax competition on a parallel network, European Economic Review 49, 2013-2040.

De Borger , B., Dunkerley, F. and S. Proost, 2007, Strategic investment and pricing decisions in a congested transport corridor, Journal of Urban Economics 62, 294-316.

de Palma, A. and R. Lindsey, 2007, Transport user charges and cost recovery, in de Palma, Lindsey and Proost (Eds.), Investment and the use of tax and toll revenues in the transport sector, Elsevier Publishing, 29-57.

Mohring, H. and M. Harwitz, 1962, Highway benefits: An analytical framework, Northwestern University Press, Evanston, Illinois.

Morrisson, S.A., 1983, Estimation of long-run prices and investment levels for airport runways, Research in Transportation Economics 1, 103-130.

Zhang, A. and Y. Zhang, 2003, Airport charges and capacity expansion: effects of concessions and privatization, Journal of Urban Economics 53, 54-75. 


\section{Appendix 1: Proof of Proposition 1}

Start from the optimal capacity and corresponding capacity cost for the case of an infrastructure with constant returns to scale (zero fixed cost). Denote the variable cost of capacity by $k^{*}$; optimal capacity is denoted $Z^{*}$, hence optimal capacity cost for this case is $C^{*}=k^{*} Z^{*}$.

Then consider the isocost/isocapacity structure $C^{*}-k Z^{*}=F$ describing all combinations of fixed and variable cost $(F, k)$ that yield, for the given capacity $Z^{*}$, the same total cost $C^{*}$. This isocost-isocapacity line can be written as:

$$
F=\left(k^{*}-k\right) Z^{*}
$$

Remember the welfare function is given by:

$$
W_{\text {reg }}=\int_{0}^{Y} P^{Y}(y) d y-g^{Y} Y+\theta Y-F-k Z
$$

Substituting (A1) implies

$$
W_{\text {reg }}=\int_{0}^{Y} P^{Y}(y) d y-g^{Y} Y+\theta Y-k^{*} Z^{*}+k\left(Z^{*}-Z\right)
$$

Now consider the welfare impact of a change in the cost structure along an isocostisocapacity line. Specifically, consider a change in variable cost $k$ (and, hence, a corresponding change in fixed cost); the effect on welfare is given by:

$$
\frac{d W}{d k}=\frac{\partial W}{\partial k}+\frac{\partial W}{\partial Z} \frac{\partial Z^{o p t}}{\partial k}
$$

where we have deleted the subscript ${ }_{\text {reg }}$ to save on notation, and $Z^{\text {opt }}$ is the optimal capacity associated with the welfare optimization program (A2). Noting that the firstorder condition for optimal capacity implies $\partial W / \partial Z=0$, we can simplify (A3) to $\frac{d W}{d k}=\frac{\partial W}{\partial k}$. Differentiating (A2), we immediately obtain:

$$
\frac{\partial W}{\partial k}=-Z^{o p t}+Z^{*}
$$

To show that an increase in the fixed cost along an isocost-isocapacity locus raises welfare it suffices to show that the right-hand-side of (A4) is negative, since higher variable cost is equivalent to lower fixed cost. To show that this is the case, note that, since $Z^{*}$ corresponds to optimal capacity at variable capacity cost $k^{*}$, the inequality $Z^{o p t}>Z^{*}$ will hold provided that $\partial Z^{\text {opt }} / \partial k<0$. But this directly follows from the first order condition on capacity, $d W / d Z=0$, which evaluated at the optimum took the form (see expression in the main body of the paper)

$$
C^{\prime} Y^{2}-k\left(Z^{o p t}\right)^{2}=0
$$

Indeed, letting $f$ denote the left hand side of (A5), the implicit function theorem tells us that

$$
\frac{\partial Z^{o p t}}{\partial k}=-\frac{\frac{\partial f}{\partial k}}{\frac{\partial f}{\partial Z^{o p t}}}
$$


The denominator of (A6) is negative by the second order condition for optimal capacities. Simple differentiation yields that the numerator $\frac{\partial f}{\partial k}=-\left(Z^{o p t}\right)^{2}<0$. Hence, (A6) is negative. This completes the proof.

\section{Appendix 2: Proof of Proposition 2}

In the case of through traffic we analogously show that higher fixed costs along an isocost-isocapacity line raises welfare. First, following the same logic as in the proof of Proposition 1 in Appendix 1 (substituting (A1) in the objective function (7) for the case with through traffic), that $\frac{d W}{d k}=\frac{\partial W}{\partial k}<0$. Moreover, we again have immediately that:

$$
\frac{\partial W}{\partial k}=-Z^{o p t}+Z^{*}
$$

This will be negative provided $\partial Z^{\text {opt }} / \partial k<0$.

To show that this holds, note that for the case with through traffic, the first-order condition on capacity (see 13) can be written in the form $G(Z)-k Z^{2}=0$, where the function $G(Z)$-- i.e., the left hand side of (13) -- is independent of $k$. Indeed, marginal investment costs do not appear in the optimal toll rule (12) nor in the demand and congestion functions. Denoting $h(k, Z)=G(Z)-k Z^{2}=0$ and again appealing to the implicit function theorem, we can therefore write

$$
\frac{\partial Z^{o p t}}{\partial k}=-\frac{\frac{\partial h}{\partial k}}{\frac{\partial h}{\partial Z^{o p t}}}
$$

The denominator is again negative by the second order condition for optimal capacities. The numerator yields $\frac{\partial h}{\partial k}=-\left(Z^{o p t}\right)^{2}<0$. This completes the proof.

\section{Appendix 3: Summary proof of Proposition 3}

Assume regions impose no tolls, but only compete in capacities. The first order conditions for optimal capacity in each region implicitly define the reaction functions in capacities. Solving these reaction functions, we can then write the Nash equilibrium capacities in general as a function of the variable cost parameters in the two regions:

$$
\begin{aligned}
& Z_{A}^{N E}=Z_{A}\left(k_{A}, k_{B}\right) \\
& Z_{B}^{N E}=Z_{B}\left(k_{A}, k_{B}\right)
\end{aligned}
$$

Welfare levels at the Nash equilibrium are obtained by substituting the Nash equilibrium capacities into the respective welfare functions; they can be written in general:

$$
\begin{aligned}
& W_{A}^{N E}=W_{A}\left(Z_{A}^{N E}, Z_{B}^{N E}, k_{A}\right) \\
& W_{B}^{N E}=W_{B}\left(Z_{A}^{N E}, Z_{B}^{N E}, k_{B}\right)
\end{aligned}
$$


To study the effect of an increase in the fixed cost share in A on welfare at the Nash equilibrium for A, we totally differentiate to obtain:

$$
\frac{d W_{A}}{d k_{A}}=\frac{\partial W_{A}}{\partial k_{A}}+\frac{\partial W_{A}}{\partial Z_{B}} \frac{\partial Z_{B}^{N E}}{\partial k_{A}}
$$

where we have used the fact that optimal capacity in A implies that $\frac{\partial W_{A}}{\partial Z_{A}}=0$. Expression (A8) shows that the effect of a change in the cost structure has a direct and an indirect component. The first term on the right hand side is the direct effect. As in the proofs of Propositions 1 and 2, we again have:

$$
\frac{\partial W_{A}}{\partial k_{A}}=-Z_{A}+Z_{A}^{*}
$$

This can again be shown to be negative, using exactly the same procedure as before. So the direct effect of higher fixed cost shares is to raise welfare.

The second component on the right hand side of (A8) captures the effect of changes in the cost structure in A on welfare in A via the strategic response of region B. The cost change in A affects optimal capacity in B (because it affects capacity in A and hence through traffic, which induces $B$ to optimally respond by adjusting capacity); the capacity change in B in turn affects welfare in region A. To study the sign of these effects note that, using (7) and the fact that tolls are zero, $\frac{\partial W_{A}}{\partial Z_{B}}$ is easily shown to be negative. This makes intuitive sense: more capacity in B raises through traffic and, therefore, reduces welfare in A.

Finally, the effect of variable capacity cost in region A on Nash equilibrium capacities in B is ambiguous. However, differentiating system (A7) it easily follows that the term $\frac{\partial Z_{B}^{N E}}{\partial k_{A}}$ has the same sign as the slope of the reaction function in capacities. This makes sense: if variable capacity cost in A rises along an isocostisocapacity line (hence fixed cost goes down) capacity in A will decline; this will reduce (raise) capacity in B if reaction functions are upward (downward) sloping. Although the numerical analysis suggests that reaction functions are very plausibly upward sloping, this need not generally be the case.

In summary, the first term on the right hand side of (A8) is negative, the second term is positive (negative) if capacity reaction functions are upward (downward) sloping. The numerical analysis suggests that the first term dominates, however, so that raising the fixed cost share is welfare improving. 